Raaijmakers, M.F., Dekker, J., Dejonckere, P.H. Diagnostic assessment and treatment goals in logopedics: impairments, disabilities and handicaps. Folia Phoniatrica et Logopaedica: 1998, $50,71-79$

\begin{tabular}{|l|l|}
\hline $\begin{array}{l}\text { Postprint } \\
\text { Version }\end{array}$ & 1.0 \\
\hline $\begin{array}{l}\text { Journal website } \\
\text { Pubmed link }\end{array}$ & $\underline{\text { http://content.karger.com/produktedb/produkte.asp?typ=fulltext\&file=fpl50071 }}$ \\
\hline DOI & $\underline{10.1159 / 000021452}$ \\
\hline
\end{tabular}

This is a NIVEL certified Post Print, more info at http://www.nivel.eu

\title{
Diagnostic Assessment and Treatment Goals in Logopedics: Impairments, Disabilities and Handicaps
}

\author{
M.F. RAAIJMAKERS ${ }^{A} J^{\text {DE DKKER }}{ }^{A}$ P.H. DEJONCKERE ${ }^{B}$ \\ ${ }^{\mathrm{a}}$ Netherlands Institute of Primary Health Care and ${ }^{\mathrm{b}}$ Institute of Phoniatrics, Utrecht, The \\ Netherlands \\ J. Dekker Netherlands Institute of Primary Health Care PO Box 1568 NL-3500 BN Utrecht \\ (The Netherlands) Tel. 31302319946, Fax 31302319290, E-Mail j.dekker@nivel.nl
}

\begin{abstract}
This study was aimed to investigate to what extent impairments, disabilities and handicaps are used as diagnostic assessments and treatment goals in logopedics. Traditionally, logopedists are mainly concerned with impairments. These days, increasing attention is demanded for disabilities and handicaps as well. A survey study was carried out on 1,567 patients in logopedic practices in the Netherlands to provide an empirical quantitative description of diagnostic assessments and treatment goals, formulated in terms of impairments, disabilities and handicaps. Results show that logopedists indeed often indicate impairments as diagnostic assessments and as treatment goals, particularly language development impairments and phonetic/ phonological articulation impairments. Interestingly, also large numbers of diagnostic assessments and treatment goals were indicated at the level of disabilities and handicaps; the most important being disability in expressing communication and occupational handicap. These results demonstrate that disabilities and handicaps may serve an important function in logopedics, in that they may guide assessment as well as therapy. It is concluded that disabilities and handicaps should be considered in the future development of the profession of logopedics.
\end{abstract}

There is a close relation between logopedics and medicine, although both professions have their own responsibilities for patients entering their practice. Treatment of physicians is based upon medical diagnosis, which is primarily concerned with the aetiology or pathogenesis of a disorder [1, 2]. Diagnostic assessment ${ }^{1}$ in logopedics complements this medical diagnosis, as it focuses on the consequences of the disorder. For example, in a patient with the medical diagnosis 'cleft palate', the logopedist could formulate his diagnostic assessment in terms such as 'nasality' and 'lack of intelligibility', and select his interventions in accordance with these assessments. Thus, logopedists are concerned with the

\footnotetext{
${ }^{1}$ In this article the term 'diagnostic assessment' is used to refer to the conclusions the logopedist arrives at as a result of his/her own examination and observations.
} 
Raaijmakers, M.F., Dekker, J., Dejonckere, P.H. Diagnostic assessment and treatment goals in logopedics: impairments, disabilities and handicaps. Folia Phoniatrica et Logopaedica: 1998, $50,71-79$

functional behaviour of speech organs and with the communicative functioning of the patient.

The International Classification of Impairments, Disabilities and Handicaps (ICIDH) [3] is regarded as an excellent framework for diagnostic assessments of problems in functional health (instead of pathology) [4]. In this classification an impairment is defined as 'any loss or abnormality of psychological, physiological or anatomical structure or function' [3, p. 47]. For example voice impairments. A disability is 'any restriction or lack (resulting from an impairment) of ability to perform an activity in the manner or within the range considered normal for a human being' [3, p. 143]. An example is a disability in eating and/or drinking. A handicap is defined as 'a disadvantage for a given individual, resulting from an impairment or disability, that limits or prevents the fulfillment of a role that is normal (depending on age, sex, and social and cultural factors) for that individual' [3, p. 183]. An example is an occupational handicap in a teacher with voice impairment. Use of these ICIDH concepts is considered to be extremely useful in the context of audiological rehabilitation [5] and for measuring outcome in logopedics [6, 7].

Traditionally, diagnostic assessments in logopedics are formulated in terms of disturbances at the organ level or at the level of physiological or psychological function, which may be considered as impairments according to the ICIDH. Thus in logopedic handbooks and in classifications of speech and language disorders, emphasis is mainly on impairments. This results in well-known categories like for example voice disorders, hearing disorders, articulation disorders, (developmental) language disorders, disorders in fluency and rhythm (disorders of speech flow), etc. [8-10].

As a disorder of communication affects almost all aspects of a person's life, logopedics is also engaged in the personal, social and occupational life of clients [11]. Therefore, increasing attention is now demanded for the levels of disabilities and handicaps in the field of logopedics. As Enderby [6] points out: 'Therapists work not only in the area of impairment, but also with disability and handicap. The emphasis will often be different according to the disease or disorder, and to the patient's and carer's needs, residual skills and preferences'.

Because the distinction in impairments, disabilities and handicaps is a relatively new concept, little is known about its empirical value in logopedics. It is not known to what extent logopedists would now direct their diagnostic assessments in their patients on either impairments, or on disabilities and handicaps. Therefore the first aim of this study is to investigate to what extent logopedists use impairments as diagnostic assessment and to what extent their diagnostic assessments are concerned with the level of disabilities and handicaps.

The primary purpose of diagnostic assessment is to determine what the logopedist should do to assist the improvement of communication [2]. Once it is determined that treatment is needed, the logopedist will propose a therapy plan, which includes the objectives of the treatment $[12,13]$. These treatment goals can be derived from the diagnostic assessment. In one patient, several impairments, disabilities and handicaps may be assessed [4, 5]. It is assumed that just a few of these serve as treatment goals actually guiding therapy. It would be interesting to investigate to what extent treatment goals are chosen at the level of impairments or at the level of disabilities and handicaps.

Thus, in this article two questions will be answered. First, to what extent are not only the (traditional) level of impairments, but also disabilities and handicaps used for diagnostic assessments in logopedic practices? Second, to what extent are assessments at these three levels selected as treatment goals for guiding therapy? 
Raaijmakers, M.F., Dekker, J., Dejonckere, P.H. Diagnostic assessment and treatment goals in logopedics: impairments, disabilities and handicaps. Folia Phoniatrica et Logopaedica: 1998, $50,71-79$

\section{METHOD}

\section{Design}

A survey study has been conducted to collect data on patients applying for logopedics. In the period September 1993 to September 1994, 172 therapists in 103 practices or departments took part in this study. The first 6 months were used to include new patients in the study. The registration form had to be completed after a maximum of 6 months, so the second half year was used as an extension period for treatments in progress. The participating logopedists were randomly selected from the address files of the Dutch Association of Logopedics (NVLF) as well as the Chief Inspectorate of Public Health in the Netherlands (GHI). Logopedists who volunteered were then selected according to the field in which they would be able to participate. On the basis of an earlier investigation [14], four fields were selected covering $88.9 \%$ of the total of logopedics in the Netherlands. These fields are: (1) institutional care (hospitals, nursing homes, rehabilitation centres); (2) private practice; (3) community care (for children in primary schools); (4) special schools (e.g. for children with learning/ behavioural disorders). Logopedists working in other fields, for example audiological centres and day centres for the elderly, were excluded from participation in the study to provide for coherent groups.

\section{Logopedists}

Most logopedists participating in this study were female (94\%). The mean age of the logopedists in the study was 34.4 years (minimum 24 years, maximum 57 years). These data are in concordance with the results of other studies $[14,15]$. The mean number of years that the logopedists had practised in the profession was 10.6 years.

\section{Registration Form}

In order to collect data on patients, a standard registration form was used. In this form, three sections were distinguished. In the first section patient characteristics were recorded, such as gender, date of birth and indications for referral or medical diagnosis. These indications were established by the referring physician and classified afterwards according to the International Classification of Diseases (ICD-10) [16]. However, in this survey no indication for referral or medical diagnoses was available for more than one third of the patients. In the second section, the logopedists could indicate which diagnostic assessments were made. The third section of the registration form included information on treatment goals and interventions. The first and second sections of the form were filled in as soon as the logopedist had made the assessment. The third section in the registration form was filled in as soon as the treatment was ended, or after the permitted registration period of a maximum of 6 months per patient.

The standard list of diagnostic assessments for logopedics that was used in the form was based on the ICIDH. The ICIDH in its original form is rather impractical and timeconsuming for use in logopedics, both because a number of items are not relevant for use in the profession, and because terminology is uncommon in logopedics. Relevant items were therefore selected from the ICIDH and where necessary modified for use in logopedics with the help of an expert panel. The inter-rater reliability of this list showed satisfactory to good agreement for diagnostic assessments in this list $[17,18]$.

Logopedists participating in the present study received instructions on how to register diagnostic assessments on the form. One instruction worth mentioning here read that in case the impairment 'dysarthria' was diagnosed, additional impairments in either voice, articulation, nasality, fluency and sensorimotor functioning were not to be scored. These 
Raaijmakers, M.F., Dekker, J., Dejonckere, P.H. Diagnostic assessment and treatment goals in logopedics: impairments, disabilities and handicaps. Folia Phoniatrica et Logopaedica: 1998, $50,71-79$

impairments were considered to be inherent to dysarthrias. Furthermore, logopedists were allowed to register as many diagnostic assessment categories as needed, but only a maximum of five treatment goals.

\section{Procedure}

Logopedists were instructed to include in the survey all patients applying for logopedics, immediately after the start of the registration period. The number of patients to be registered in each location was agreed upon preceding the start of the study. In each field the total number of patients was planned to be in proportion to the relative percentage of that field [14].

In total 1,761 patients were included in the study. Distribution across the four fields turned out as was planned. The proportion of institutional care was $20.9 \%$ (planned: $20 \%$ ), private practice $29.4 \%$ (planned: $30 \%$ ), community care $18.5 \%$ (planned: $19 \%$ ) and special schools 31.1\% (planned: 31\%).

\section{Data Analysis}

First a quantitative description is given of the characteristics of patients in this study. Second, quantitative analysis is presented of the diagnostic assessments and treatment goals. For this analysis, assessments were combined into main categories. A main category was counted as being present in a patient, as soon as at least one sub-item of that category was registered. As this study is focused on the relationship between diagnostic assessments and treatment goals, 194 patients who did not receive any treatment were excluded from the quantitative analyses. This means descriptions will be presented of 1,567 patients.

\section{RESULTS}

\section{Patients and Indications for Referral}

Table 1 shows some characteristics of the patients. Most patients were male. A vast majority of the patients was under the age of 18 years.

Medical indications for referral, coded according to the main chapters of the ICD-10, are presented in table 2. For 560 patients (35.7\%) neither indication for referral nor medical diagnosis was known to the logopedist. The indications for referral show a great variety. Most important is the ICD-10 chapter 'Psychological and Behavioural Diseases'; this group includes specific developmental disorders of speech and language, stuttering and specific developmental disorders of motor function, among others. Another large group is 'Symptoms, Signs and Abnormal Clinical and Laboratory Findings, Not Elsewhere Classified'. In this group, four major disorders are voice disturbances, dysphasia and aphasia, dysarthria and anarthria and dysphagia. The chapter 'Diseases of the Circulatory System' includes cerebrovascular diseases, and within the group of 'Diseases of the Respiratory System', the main diagnoses are concerned with diseases of vocal cords and larynx (for example nodules, polyps).

[TABLE 1]

[TABLE 2] 
Raaijmakers, M.F., Dekker, J., Dejonckere, P.H. Diagnostic assessment and treatment goals in logopedics: impairments, disabilities and handicaps. Folia Phoniatrica et Logopaedica: 1998, $50,71-79$

\section{Diagnostic Assessments and Treatment Goals}

Table 3 shows the impairments, disabilities and handicaps that were diagnosed and indicated as a treatment goal. At the level of impairments, the diagnostic assessment categories phonetic/phonological articulation impairments and language development impairments were indicated most frequently, 43.3 and $42.3 \%$, respectively. Table 3 shows that these impairment categories were also most often selected as treatment goals (32.6 and $37.0 \%)$. The impairments nasality and dysarthria were indicated the least, both as a diagnostic assessment (5.2 and 5.8\%, respectively) and as a treatment goal (4.1 and 4.6\%).

At the level of disabilities, the disability in expressing communication was diagnosed in $62.4 \%$ of the patients, followed by the disability in understanding communication (43.3\%). These two disabilities were also most often selected as treatment goals (38.1 and 19.5\%, respectively). The disability in eating and drinking was indicated the least by logopedists, in $10.2 \%$ of the patients as a diagnostic assessment and in $7.3 \%$ as a treatment goal.

At the level of handicaps, the most often registered diagnostic assessments were occupational handicap (50.0\%) and handicap in social integration outside of family (44.9\%). These handicaps were also most often selected as treatment goals, be it to a lesser degree of 12.2 and $11.0 \%$, respectively.

Finally, information on the general distribution of impairments, disabilities and handicaps as treatment goals over all patients provides an overview of the findings of this study. In table 4, the relative distribution of treatment goals aimed at the level of impairments, disabilities and handicaps is given. This table presents the percentage of patients for which logopedists had indicated at least one treatment goal. It is shown that in $98.7 \%$ of the patients, at least one treatment goal was aimed at the level of impairments. Interestingly, in about half of the patients (51.2\%) at least one treatment goal was aimed at the level of disabilities. The lowest percentage was found at the level of handicaps. Still, almost a quarter of all patients was indicated at least one treatment goal at this level.

\section{[TABLE 3]}

\section{[TABLE 4]}

\section{DISCUSSION}

In this survey, it was studied to what extent logopedists would indicate their diagnostic assessments and treatment goals at the level of disabilities and handicaps, in addition to the level of impairments which was expected to be more common to logopedists.

This study shows that logopedists most frequently indicated diagnostic assessments as well as treatment goals at the level of impairments. This was to be expected because classifications in the profession traditionally have been formulated in impairment terms. However, an interesting result of this survey is that logopedists also indicated a large number of disabilities and handicaps to describe not only diagnostic assessments, but treatment goals as well. So it seems that the three conceptual levels of the ICIDH are all important in the profession of logopedics. We agree with Enderby [6] that the value of the ICIDH for logopedics is that it assists the shift in emphasis from the pathology of a disease to its consequences and that this approach also allows therapy to define its goals, which are not always impairment- oriented, in a precise and holistic way.

Diagnostic assessments and treatment goals are a suitable tool to characterize a profession [4]. From the results of this survey, the following characterization may be given of the 
Raaijmakers, M.F., Dekker, J., Dejonckere, P.H. Diagnostic assessment and treatment goals in logopedics: impairments, disabilities and handicaps. Folia Phoniatrica et Logopaedica: 1998, $50,71-79$

profession of logopedics. At the level of impairments, phonetic/phonological articulation impairments and language development impairments were most often registered as diagnostic assessments and as treatment goals. Generally speaking, logopedics as a whole will be mainly occupied with the assessment and therapy of these communication problems. At the level of disabilities, the disability in expressing communication was most often registered as a diagnostic assessment as well as a treatment goal. This implies that an important characterization of logopedics in general is the concern for enhancing patients to express themselves. At the level of handicaps the occupational handicap was most often registered for both diagnostic assessments and for treatment goals. The eventual effects of communication disorders on the occupation of patients are regularly mentioned, but may not be classified as logopedic assessments or treatment goals.

Our empirical findings clearly show that logopedists do not only work in the area of impairments, but also with disabilities and handicaps. It is important for the profession to not only focus on impairments, but also on disabilities and handicaps as this will help logopedists to adjust their care to the specific needs of their patients.

Some procedural aspects of this study should be considered, as these may differ from other studies. First, the present study is concerned with clinical assessments of logopedists. This means that no attention was paid to the precise method or measurements on which these assessments were based. For example, we did not ask for exact measurements of airflow in order to allow for the assessment 'nasality'. Second, as we did not impose objective criteria for the assessments, differences may arise among logopedists. For example, assessments might be influenced by the training and education of logopedists. However, the reliability with which the assessments were made proved to be satisfactory to good $[17,18]$. For the purpose of survey research, this list of diagnostic assessments therefore was considered to be a suitable tool.

The use of the ICIDH-based terms of impairments, disabilities and handicaps in logopedics may be of importance for the future development of our profession. Usage of the ICIDH terminology will improve the communication among logopedists. And as this terminology is now implemented more and more into other allied health professions [4] and rehabilitation [5, 6], using the ICIDH terminology will also enhance communication with other professions. Furthermore, the ICIDH could provide a basis to design communitybased studies to estimate the prevalence of speech and language problems [19]. Such estimates are needed for service planning. Finally, the use of impairments, disabilities and handicaps in logopedics offers a useful means for future research on outcome measurement. To measure the change related to the logopedic treatment, it is insufficient to rely on medical classification and diagnosis. Instead, Enderby [6, 7] proposed to define both the disorder and the goals of therapy in terms of the ICIDH. In connection with this, there is now a growing need for diagnostic tests and procedures for each impairment, disability and handicap [4].

In conclusion, application of the conceptual levels of impairment, disability and handicap seems highly appropriate for the profession of logopedics. Especially the introduction of disabilities and handicaps as defined by the ICIDH is considered to be of great value for logopedic practice and research. By using these relatively new concepts, logopedists will be able to adapt their care to the specific needs of their patients and reveal the complex diagnostic assessments and therapeutic activities that are carried out.

\section{REFERENCES}

1 Aronson AE: The clinical PhD: Implications for the survival and liberation of communicative disorders as a health care profession. ASHA 1987;29:35-37.

2 Perkins WH: Speech Pathology: An Applied Behavioral Science. Saint Louis, Mosby, 1971. 3 World Health Organisation: International Classification of Impairments, Disabilities and Handicaps (ICIDH). Geneva, WHO, 1980. 
Raaijmakers, M.F., Dekker, J., Dejonckere, P.H. Diagnostic assessment and treatment goals in logopedics: impairments, disabilities and handicaps. Folia Phoniatrica et Logopaedica: 1998 $50,71-79$

4 Dekker J: Application of the ICIDH in survey research on rehabilitation: The emergence of the functional diagnosis. Disabil Rehabil 1995;17: 195-201.

5 Stephens D, Hétu R: Impairment, disability and handicap in audiology: Towards a consensus. Audiology 1991;30:185-200.

6 Enderby P: Outcome measures in speech therapy: Impairment, disability, handicap and distress. Health Trends 1992;24:61-64.

7 Enderby P: Therapy Outcome Measures in Speech-Language-Pathology. San Diego, Singular, 1997.

8 Sonninen A, Damsté PH: An international terminology in the field of logopedics and phoniatrics. Folia Phoniatr 1971;23:1-32.

9 ASHA: ASHA classification of speech-language pathology and audiology procedures and communication disorders. ASHA 1987;29:49- 53.

10 CPLOL (Comité Permanent de Liaison des Orthophonistes Logopèdes de la CEE):

Professional profile of the speech therapist; in CPLOL: Press Book. Paris, CPLOL, 1991.

11 Hegde MN: Principles of management and remediation; in Lass NJ, McReynolds LV, Northern JL, Yoder DE (eds): Handbook of Speech- Language Pathology and Audiology. Toronto, Decker, 1988, pp 377- 393.

12 Nation JE, Aram DM: Diagnosis of Speech and Language Disorders. San Diego, CollegeHill Press, 1984.

13 Kuiper HM: Methodisch handelen in de logopedie (A Methodological Approach to Logopedics). Groningen, Styx, 1989.

$14 \mathrm{GHI}$ (Chief Inspectorate of Public Health): Beroepsuitoefening van logopedisten (Practice of the Profession of Logopedics). Rijswijk, GHI, 1990.

15 Raaijmakers MF, Dekker J: Logopedie in de Nederlandse gezondheitszorg (Logopedics in Dutch health care). Logopedien Foniatrie 1995;9: 206-217.

16 World Health Organisation: International Classification of Diseases (ICD), revision 10. Geneva, WHO, 1990.

17 Raaijmakers MF, Dekker J, Dejonckere PH, Van der Zee J: Reliability of the assessment of impairments, disabilities and handicaps in survey research in speech therapy. Folia Phoniatr Logop 1995;47:199- 209.

18 Raaijmakers MF, Dekker J: Toepassing van de ICIDH in de logopedie (Application of the ICIDH in Logopedics). Utrecht, NIVEL, 1993.

19 Enderby P, Philipp R: Speech and language handicap: Towards knowing the size of the problem. Br J Disord Commun 1986;21:151-165. 
Raaijmakers, M.F., Dekker, J., Dejonckere, P.H. Diagnostic assessment and treatment goals in logopedics: impairments, disabilities and handicaps. Folia Phoniatrica et Logopaedica: 1998, $50,71-79$

Table 3. Impairments, disabilities and handicaps diagnosed and chosen as a treatment goal $(\mathrm{n}=1,567)$

\begin{tabular}{|c|c|c|}
\hline & $\begin{array}{l}\text { Diagnosed } \\
\%\end{array}$ & $\begin{array}{l}\text { Treatmen } \\
\text { goal, } \%\end{array}$ \\
\hline \multicolumn{3}{|l|}{ Impairments ${ }^{l}$} \\
\hline Aural impairments & 11.2 & \multirow{2}{*}{14.6} \\
\hline Impairments of auditory functions & 19.5 & \\
\hline Voice impairments & 22.6 & \multirow{2}{*}{16.5} \\
\hline Respiratory impairments & 15.3 & \\
\hline Language development impairments & 42.3 & 37.0 \\
\hline Aphasia & 7.2 & 5.9 \\
\hline Impairments of reading and writing & 11.1 & 6.7 \\
\hline Phonetic/phonological articulation impairments & 43.3 & 32.6 \\
\hline Dysarthria & 5.8 & 4.6 \\
\hline Nasality & 5.2 & 4.1 \\
\hline Impairments of fluency and rhythm in speech & 12.7 & \multirow[t]{2}{*}{11.6} \\
\hline Deviant mouth behaviours & 31.7 & \\
\hline Impairments of swallowing & 5.6 & \multirow[t]{3}{*}{26.5} \\
\hline Sensorimotor impairments & 15.9 & \\
\hline Hyperventilation & 1.1 & \\
\hline Cognitive and psychological impairments & 30.9 & \multirow[t]{2}{*}{12.1} \\
\hline Impairment of body posture & 5.2 & \\
\hline \multicolumn{3}{|l|}{ Disabilities $^{l}$} \\
\hline Disability in understanding communication & 43.3 & 19.5 \\
\hline Disability in expressing communication & 62.4 & 38.1 \\
\hline Disability in interacting during communication & 35.2 & 17.3 \\
\hline Disability in eating and drinking & 10.2 & 7.3 \\
\hline \multicolumn{3}{|l|}{ Handicaps $^{l}$} \\
\hline Occupational handicap & 50.0 & 12.2 \\
\hline Social integration within family & 27.3 & 7.3 \\
\hline Social integration outside of family & 44.9 & 11.0 \\
\hline
\end{tabular}

1 The percentages refer to all patients. All items could be indicated.

Table 4. Patients $(n=1,567)$ with at least one treatment goal at the level of impairments, disabilities or handicaps

\begin{tabular}{llr}
\hline & \multicolumn{2}{l}{ Patients } \\
\cline { 2 - 3 } & $\%$ & $\mathrm{n}$ \\
\hline Treatment goals aimed at & & \\
$\quad$ Impairments & 98.7 & 1,547 \\
Disabilities & 51.2 & 803 \\
Handicaps & 23.9 & 374 \\
\hline
\end{tabular}

Total adds to more than $100 \%$, as several treatment goals could be registered per patient. 